Research Article

\title{
Deformation Behavior of Deep Foundation Pit under Both Overloading and Unloading Conditions
}

\author{
Wei Gang ${ }^{1},{ }^{1}$ Zhou Xin-Xin, ${ }^{2}$ Xu Yin-Feng, ${ }^{3}$ Zhang Li, ${ }^{4}$ and Zhang Xin-Hai ${ }^{5}$ \\ ${ }^{1}$ Department of Civil Engineering, Zhejiang University City College, Hangzhou 310015, China \\ ${ }^{2}$ College of Civil Engineering and Architecture, Zhejiang University, Hangzhou 310058, China \\ ${ }^{3}$ Hangzhou Survey and Design Institute, Hangzhou 310012, China \\ ${ }^{4}$ College of Chemical Engineering, Zhejiang University of Technology, Hangzhou 310000, China \\ ${ }^{5}$ College of Ocean, Zhejiang University, Zhoushan 316000, China \\ Correspondence should be addressed to Wei Gang; weig@zucc.edu.cn
}

Received 4 November 2020; Revised 19 November 2020; Accepted 10 December 2020; Published 23 December 2020

Academic Editor: Abdul Qadeer Khan

Copyright (c) 2020 Wei Gang et al. This is an open access article distributed under the Creative Commons Attribution License, which permits unrestricted use, distribution, and reproduction in any medium, provided the original work is properly cited.

\begin{abstract}
A deep foundation pit in a station of the Hangzhou subway is adjacent to new high-rise residential buildings on the north side and to the Evergrande foundation pit being excavated on the south side. This work considers the excavation of the foundation pit in the subway station as the research subject, focuses on the difference of the deformation and Earth pressure between the north side and the south side of the foundation pit under these special working conditions through the analysis of the measured data, and compares it with an ordinary foundation pit. Analyzing the measured data reveals that the horizontal displacement of the retaining wall and the ground settlement are far larger on the north side than on the south side, and both often exceed the deformation alarm value; the deformation of the ordinary foundation pit is between the deformation of the overloaded (north) side and that of the unloaded (south) side of the foundation pit. Moreover, the maximum rate of the horizontal creep of the soil and the maximum rate of the creep caused by the ground settlement on the north side of the foundation pit are larger than those on the south side of the foundation pit; the maximum rate of the horizontal creep of the ordinary foundation pit is between the two. The active Earth pressure on the pit wall on the north side is higher than that on the south side of the foundation pit, and because of the surrounding unloading, passive Earth pressure is generated at the bottom of the pit wall on the south side of the foundation pit, which causes it to shift to the outside of the foundation pit. The settlement of the surrounding high-rise buildings and the settlement of the columns are all within the range of the alarm values; also, the buildings settle evenly. Due to the excavation and unloading on the south side of the foundation pit, the uplift of the columns is not considerable.
\end{abstract}

\section{Introduction}

During the municipal construction projects, foundation pit engineering is of great importance in the field of geotechnical engineering [1]. The enclosure system of a foundation pit has a small safety reserve, and the design and construction of the pit are closely related to the surrounding environment [2], which make the foundation pit engineering has its special characteristics such as high risk and individuality [3], especially for the excavation of deep foundation pits [4]. Owing to the high risk and high difficulty of the excavation process, deep foundation pits often pose great safety hazards to people such as the collapse of the deep foundation pit in the Xianghu station of the Hangzhou subway. Therefore, monitoring and analysis of the excavation of deep foundation pits are of great significance for ensuring its safety [5].

Some works have monitored and analyzed the excavation of deep foundation pits under overloading or unloading conditions and summarized the corresponding laws. For the case where there is an overload on the pit edge, Shi et al. [6] monitored the building next to the excavation pit and found that the maximum settlement value of the building appeared at its corner, and there is a tendency for the horizontal direction to move toward the pit. Mangushev et al. [7] studied the settlement of the 
building next to the pit and found that the cause of additional settlement in building foundations during the excavation of a deep pit next to them was the loss of structure in thixotropic water-saturated bed soil and their transition to a fluid-plastic state. In another work, Wang et al. [8] studied the whole process of pit excavation and found the effect of dewatering water from the foundation pit was greater than that of the excavation on the building when the brick-concrete building structure was $34 \mathrm{~m}$ away from the foundation pit. Under the conditions of excavation and unloading on the side of a foundation pit, Ding et al. [9] examined the monitored data on the excavation of double foundation pits and discovered that the variation in the soil displacement of the foundation pit near the excavation and under unloading conditions is quite different from that of an ordinary foundation pit. Furthermore, Shi et al. [10] investigated the excavation of adjacent deep foundation pits and found that large-area excavation around a foundation pit can change the soil pressure of the pile above the excavation surface. Zeng et al. [11] studied the deformation of the perimeter walls of two adjacent abutments and found that the deflection profile of each wall in the adjacent pits showed the same pattern as that for walls in a single pit. Nonetheless, to the best of our knowledge, no work has been reported on monitoring and analysis of the excavation of deep foundation pits under simultaneous overloading and unloading conditions.

Therefore, this paper considers the excavation of a deep foundation pit in a station of the Hangzhou subway as the subject of the study; the standard section of the foundation pit is close to the high-rise residential buildings on the north side and to the Evergrande pit being excavated on the south side. Through monitoring and analysis, the difference of the settlement and deformation characteristics between the two sides of the foundation pit under special conditions of overloading and unloading is examined; then, this deep foundation pit is compared with a common pit with neither overloading nor unloading on its periphery; finally, the corresponding change law is derived, and the specific reasons for the difference between the two sides are summarized. By studying this condition, it is possible to fill the gaps in the existing research and to gain experience for subsequent excavations in similar conditions.

\section{Project Overview and Monitoring Arrangement}

The total length of the main structure of the project is $472.4 \mathrm{~m}$, and the width of the end well is $25.4 \mathrm{~m}$; the standard section of the foundation pit is $21.3 \mathrm{~m}$. The foundation pit is constructed by the open-cut construction method, and the side wall is a composite wall composed of a continuous underground wall and an inner lining wall. The thickness of the continuous wall is $0.8 \mathrm{~m}$, and the insertion ratio is in the range of 0.79 to 1.07 ; the excavation depth of the standard section is also $18 \mathrm{~m}$. The settings of the specific supporting structure of the standard section of the foundation pit are shown in Figure 1.

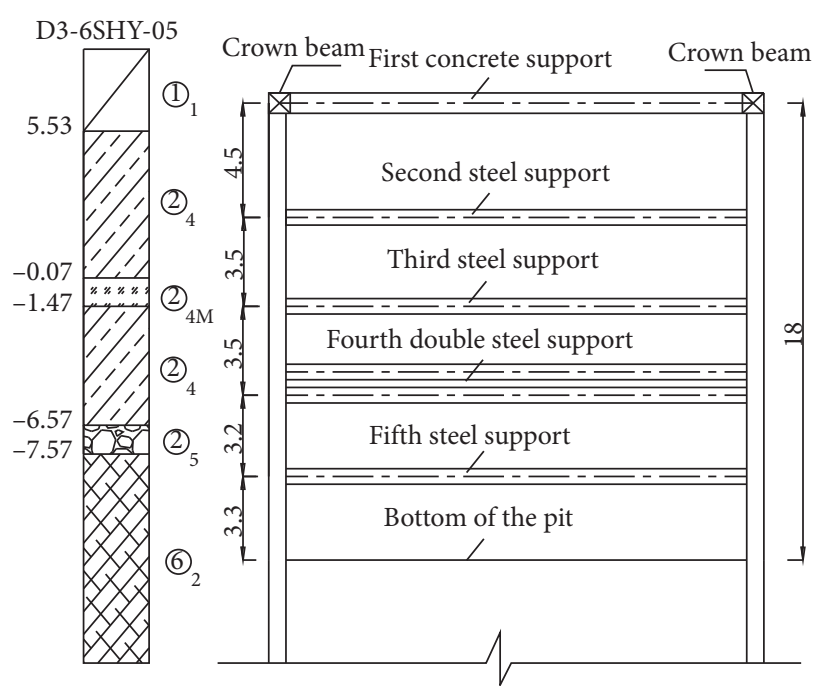

FIgURE 1: A cross-sectional diagram of the supporting structure of the standard section of the foundation pit in the subway station (unit: (m)).

2.1. Geological Conditions. The distribution of the excavated soil layers in the standard section is displayed in Figure 1, and the corresponding physical and mechanical parameters are detailed in Table 1.

2.2. Hydrological Conditions. There is no surface river in the project site, where the diving water level is generally $0.50-1.50 \mathrm{~m}$ deep at the first sight, and the static water level is generally $0.40-1.90 \mathrm{~m}$ deep. The confined water is largely distributed in the deep gravel layer with a depth of greater than $36 \mathrm{~m}$. Detailed surveys have revealed that a small amount of the confined water has a buried depth of $4.30 \mathrm{~m}$ with an annual variation of 1 to $3 \mathrm{~m}$, so it has a minimal impact on the project.

2.3. Overview of the Surrounding Environment. The foundation pit in the subway station is close to the river on the west and three pipelines on the east, which will be relocated later. The standard section, which is the focus of this paper, is close to new high-rise residential buildings, with foundations distributed to the north, and adjacent foundation pits such as those of buildings 5,6 , and 7 , where the residential buildings were backfilled prior to the excavation of the studied foundation pit. On the south side, near the Evergrande pit, the excavation depth is between 13 and $19.35 \mathrm{~m}$. During the excavation of the deep foundation pit in the subway station, the second layer of Earth in the Evergrande pit with a depth of $10 \mathrm{~m}$ at the bottom of the foundation pit is completely excavated, but the second support has not been erected yet. The surrounding environment of the deep foundation pit in the subway station is illustrated in Figures 2-4. Since the standard section of the foundation pit in the subway station is excavated at the same time as the Evergrande foundation pit, and the north side is close to the high-rise buildings, monitoring and analysis of this section is of vital importance. 
TABLE 1: The physical and mechanical parameters of the excavated stratum in the standard section of the foundation pit.

\begin{tabular}{lcccccc}
\hline Rock formation & Denomination & Unit weight $\gamma\left(\mathrm{kN} \cdot \mathrm{m}^{3}\right)$ & \multicolumn{2}{c}{$\begin{array}{c}\text { Consolidation } \\
\text { quick cut }\end{array}$} & Elastic modulus $E(\mathrm{Mpa})$ & Poisson's ratio $(\mu)$ \\
& Miscellaneous fill & & $c(\mathrm{kPa})$ & $\varphi\left({ }^{\circ}\right)$ & \\
\hline (1) & Clayey silt & 18.0 & 5.0 & 15.0 & 4 & 0.35 \\
(2) $_{4}$ & Fine sand & 18.7 & 10.6 & 26.2 & 10 & 0.25 \\
(2) $_{4 \mathrm{M}}$ & Boulder & 19.1 & 0 & 29.0 & 14.4 & 0.22 \\
(2) $_{5}$ & Silty clay with silt & 19.0 & 0 & 35.0 & 120 & 0.18 \\
(6) $_{2}$ & & 17.2 & 14.0 & 9.5 & 8.1 & 0.3 \\
\hline
\end{tabular}

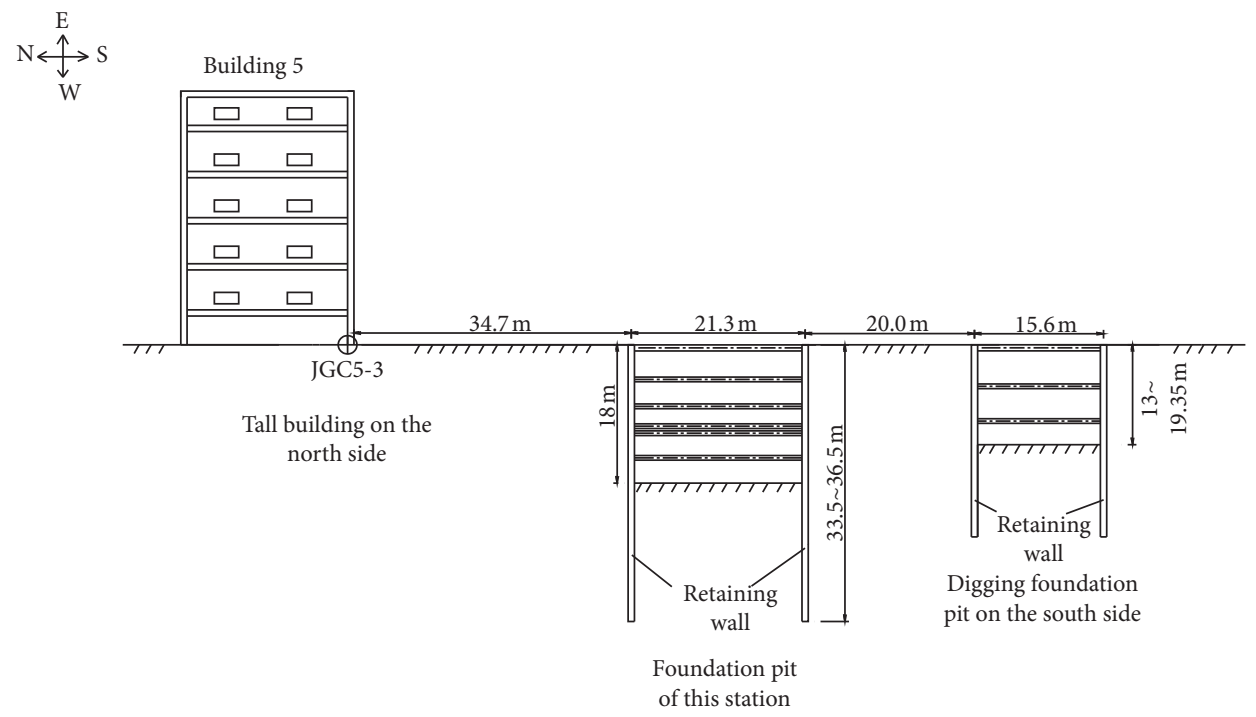

FIgURE 2: A schematic diagram of the 22-25 axes of the standard section of the foundation pit in the subway station.

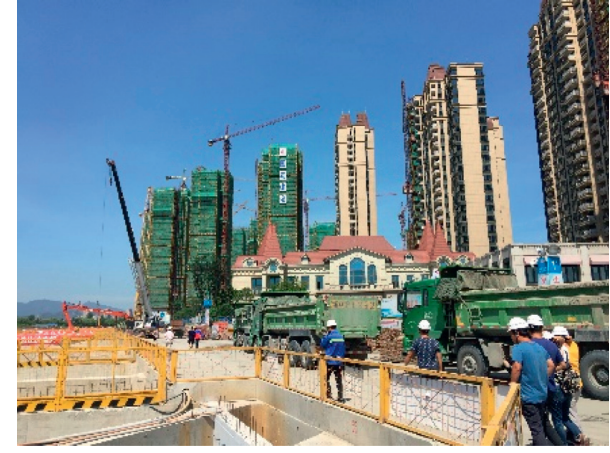

FIGURE 3: The high-rise buildings on the north side of the standard section of the foundation pit in the subway station.

\subsection{Pit Monitoring and Layout of Measurement Points.}

The main items monitored in this work include (1) the horizontal displacement of the enclosure wall, (2) the horizontal displacement of the soil, (3) the settlement of the surrounding buildings, (4) the settlement of the ground surface, and (5) the settlement of the columns. For the deep foundation pit in the subway station located between the under-construction foundation pit and the high-rise residential buildings, because the 22-25 axes of its standard section are closer to the Evergrande foundation pit on the south side and to the high-rise buildings on the north side than other axes, and the backfill of the high-rise buildings

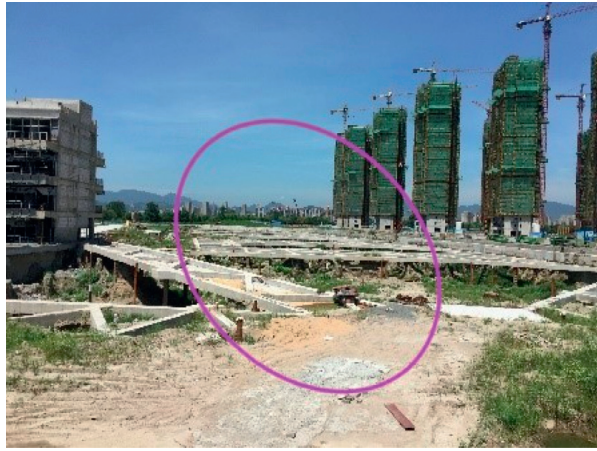

FIGURE 4: The Evergrande foundation pit located near the south side of the standard section of the foundation pit in the subway station.

has a certain time effect, which is most representative of such conditions, this paper chooses to analyze the monitored data on the 22-25 axes of the standard section of the deep foundation pit. The measurement points and cumulative deformation alarm values of each item are tabulated in Table 2, and the arrangement of the measurement points is depicted in Figure 5; the excavation conditions are also presented in Table 3.

In Table 2, the four measurement points of tall buildings are $54.4 \mathrm{~m}, 44.2 \mathrm{~m}, 34.7 \mathrm{~m}$, and $43.9 \mathrm{~m}$ from the north retaining wall in sequence. The three measurement points of 
TABLE 2: The measurement points of each parameter and the cumulative deformation alarm values.

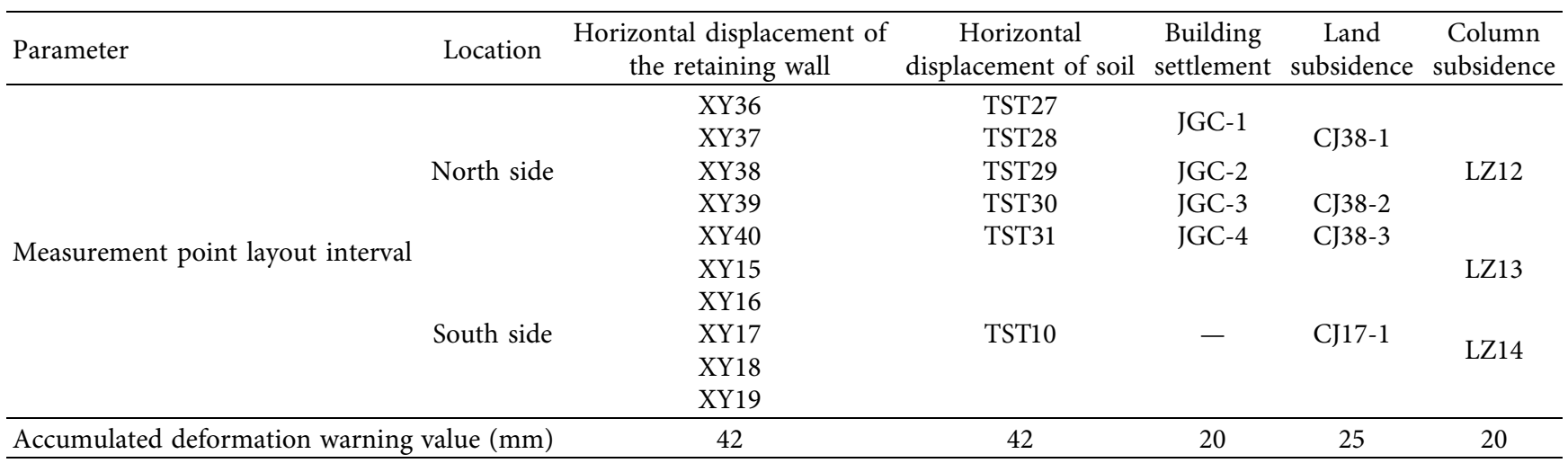

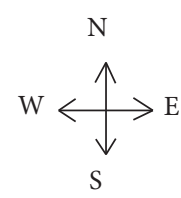

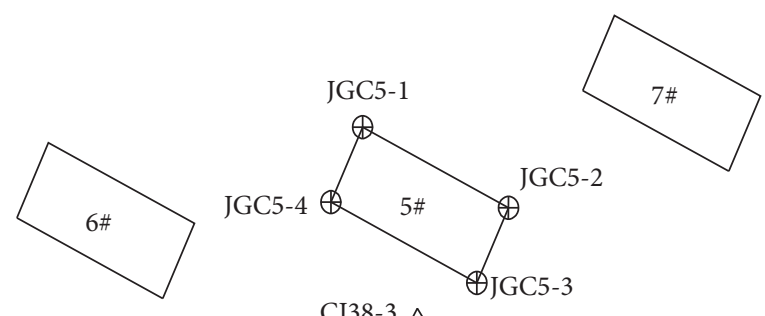

CJ38-3 $\Delta$
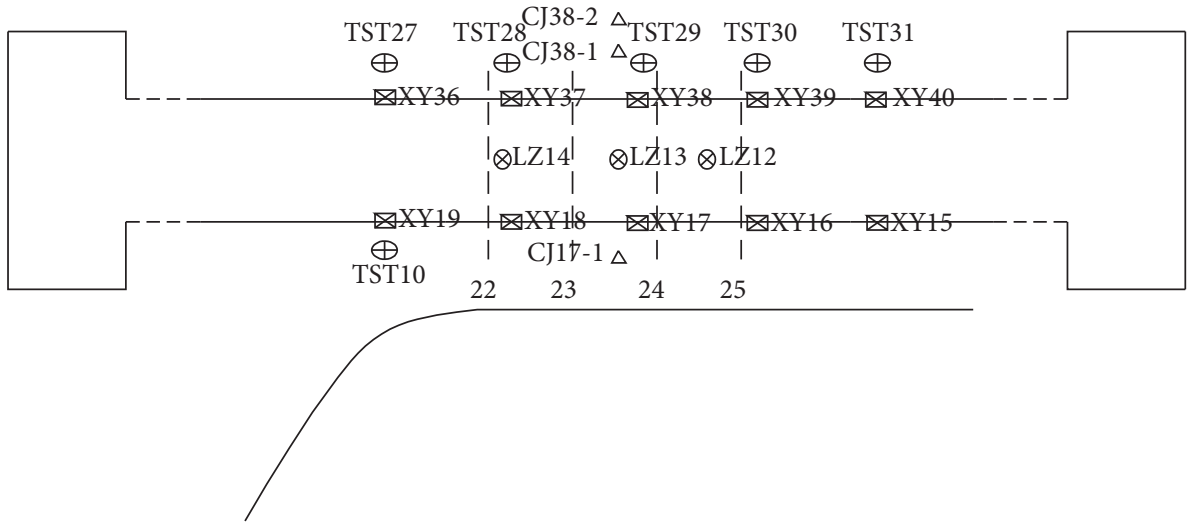

Excavation area of hengda foundation pit

$\oplus$ Settlement measurement point of building 5

$\Delta$ Surface subsidence measurement point

$\otimes$ Inclination point of retaining wall

$\oplus$ Soil horizontal displacement measuring point

$\otimes$ Column settlement measuring point

Figure 5: The layout of the measurement points of the 22-25 axes of the standard section of the foundation pit in the subway station.

the ground settlement on the north side are 2,6 , and $11 \mathrm{~m}$ from the north retaining wall in sequence. The distance between the measurement points of the ground settlement on the south side and the retaining wall of the foundation pit is $2 \mathrm{~m}$. The horizontal displacement of the retaining wall can be analyzed by means of measurement points XY37, XY38, and XY39 on the north side and measurement points XY16, XY17, and XY18 on the south side.

\section{Deformation Properties of Foundation Pit}

3.1. Comparative Analysis of Horizontal Displacement of Southern and Northern Retaining Walls. Figures 6 and 7 delineate the monitored data on the gauging slope points of the northern and southern retaining walls under different excavation conditions, respectively. The displacement of the enclosure wall into the foundation pit is positive and otherwise it is negative, with $H_{m}$ representing the maximum excavation depth and $\sigma_{\mathrm{hm}}$ indicating the maximum horizontal displacement of the retaining wall.

As shown in Figures 6 and 7, with the excavation of the foundation pit, the retaining wall is displaced horizontally to the foundation pit on the north and south sides; the deeper the excavation is, the larger the displacement of the wall becomes; further, the displacement curve of the retaining wall shows a larger variation in the middle but a small 
TABLE 3: Excavation conditions and time nodes at all levels.

\begin{tabular}{lccc}
\hline Conditions & Depth of excavation $(\mathrm{m})$ & Date & Note \\
\hline 1 & 6 & $2017 / 07 / 17$ & \\
2 & 9 & $2017 / 07 / 30$ & The excavation of the standard section is carried out from the east and west ends \\
3 & 16 & $2017 / 10 / 05$ & of the standard section to the direction of the 22-25 axes. \\
4 & 18 & $2017 / 11 / 05$ & \\
\hline
\end{tabular}

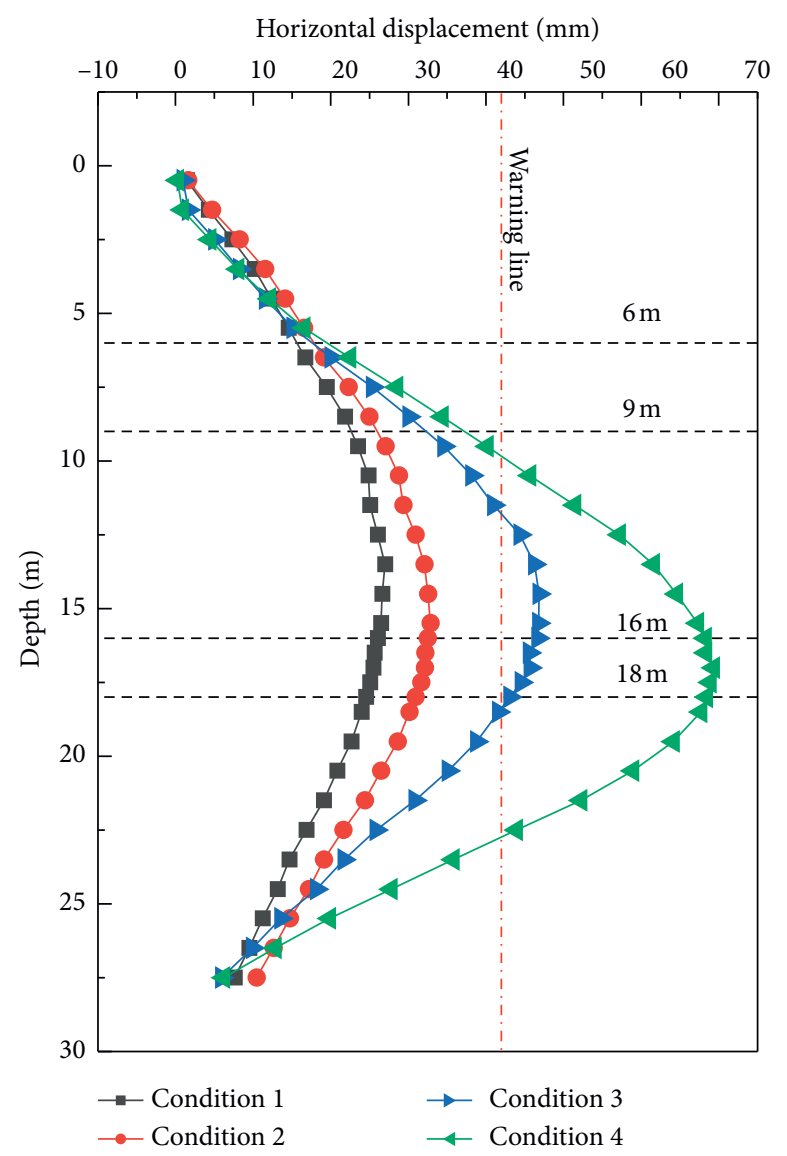

(a)

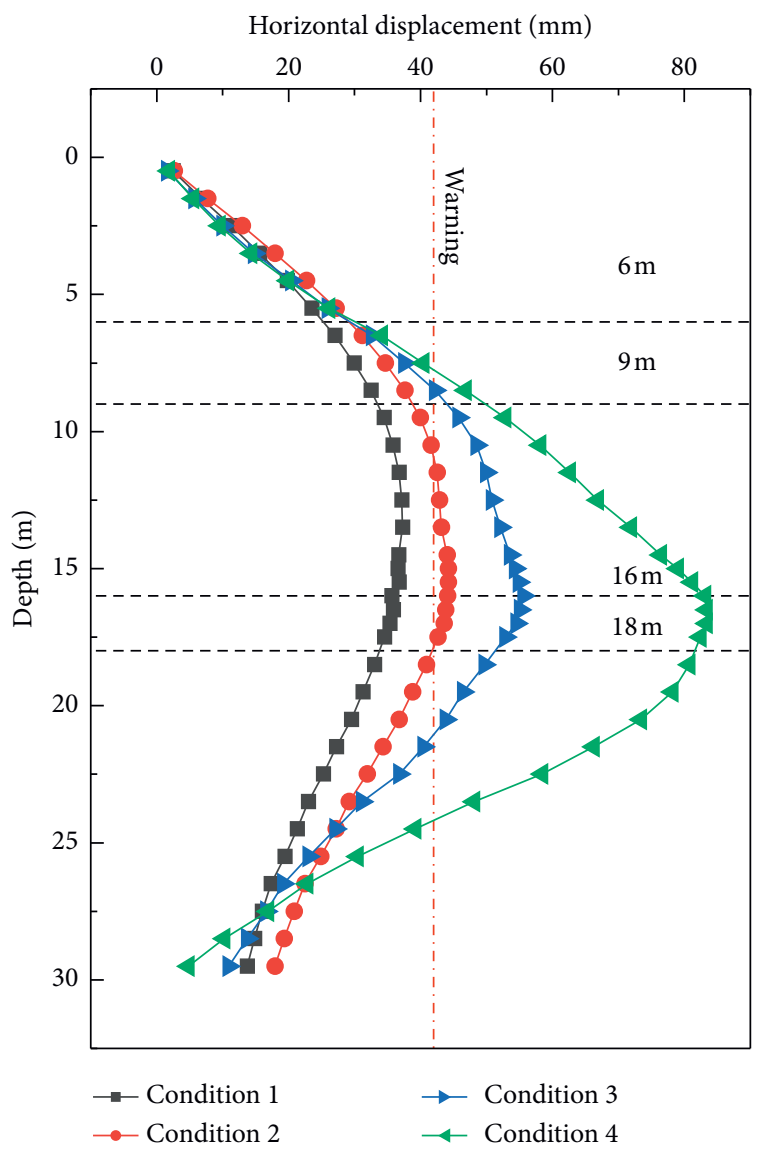

(b)

Figure 6: Continued. 


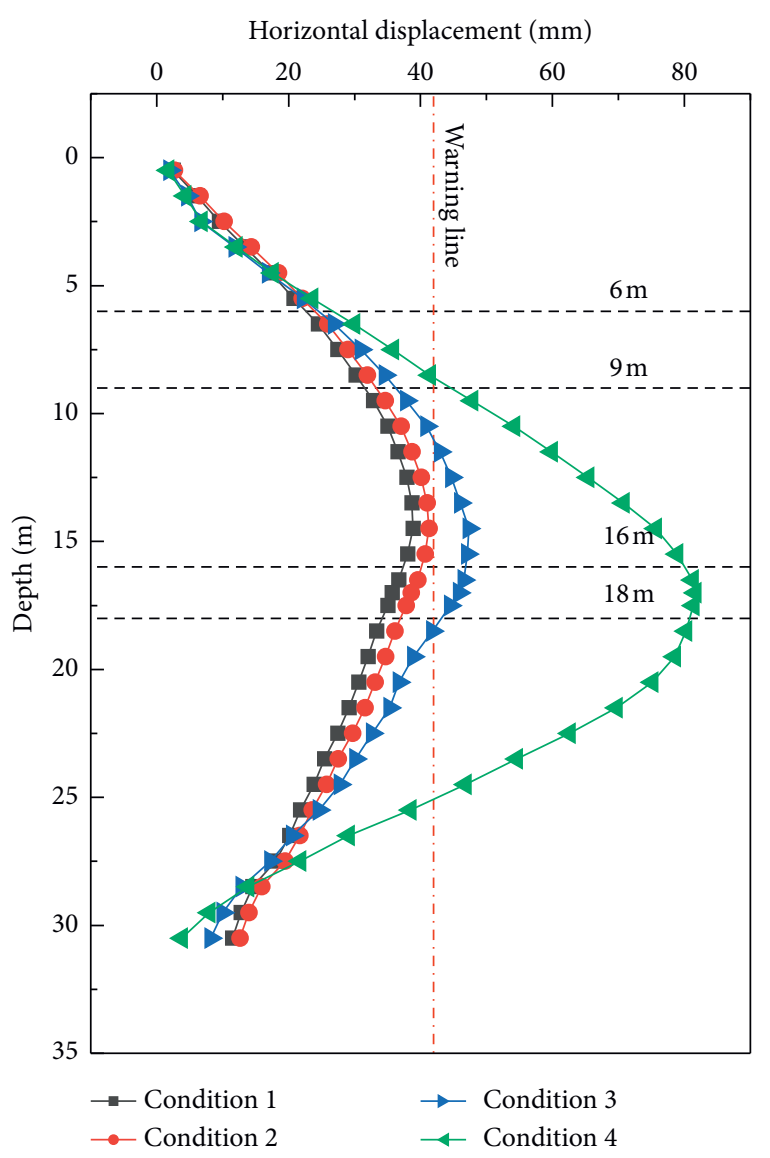

(c)

FIgURE 6: The relationship between the horizontal displacement of the retaining wall on the north side of the foundation pit and the excavation depth of the foundation pit. (a) Inclination point XY37; (b) inclination point XY38; and (c) inclination point XY39.

change at both ends, which is a typical "expansion" line type; the change trend of each level curve on the north side is in good agreement, and the south side is worse. The depths corresponding to the maximum horizontal displacement of the retaining wall measured by the measurement points on the north side of the foundation pit are all around $17 \mathrm{~m}$, while those measured by measurement points XY16, XY17, and XY18 on the south side of the foundation pit are $18,15.5$, and $16.5 \mathrm{~m}$, respectively, which indicates that the accumulated maximum horizontal displacement of the retaining wall measured by the south measurement points does not obviously correspond to a unique depth. Therefore, the deformation of the northern and southern retaining walls, which are, respectively, under overloading and unloading conditions, is not symmetrical, and the maximum horizontal displacement of them happens at different depths.

For the first-level foundation pit, the current Zhejiang standard [12] stipulates that the deformation value of the supporting structure and the control value are $0.2-0.5 \%$ of $H_{m}$; the lower range is used under complex environmental conditions; for the foundation pit in the subway station, the control value can be $0.3 \%$ of $H_{m}$. The deformation of the retaining walls on the north and south sides is depicted in Figure 8. It is obvious that the maximum displacement of the northern retaining wall is significantly larger than that of the southern retaining wall, and both displacement values largely differ from the control value of an ordinary foundation pit.

Ding et al. [13] analyzed 37 examples of deep foundation pits in soft soil in Zhejiang province and discovered that the maximum horizontal displacement was linearly related to the excavation depth of the pits. The maximum horizontal displacement of the retaining wall of the foundation pit in this work varies with the excavation depth as shown in Figure 9. It can be seen that the variation in the maximum horizontal displacement of the retaining wall at the first three levels of excavation basically conforms to a linear relationship, but it significantly increases at the last level of excavation. As shown in Figure 6, when the excavation depth is 16 and $18 \mathrm{~m}$, the cumulative horizontal displacement of the retaining wall on the north side in a depth of 10-20 m generally exceeds the warning value of $42 \mathrm{~mm}$, while that of the retaining wall on the south side of the foundation pit is lower than the warning value.

The reasons for the difference between the horizontal displacement of the retaining walls on the north and south sides and the contrast between the deformation of the 

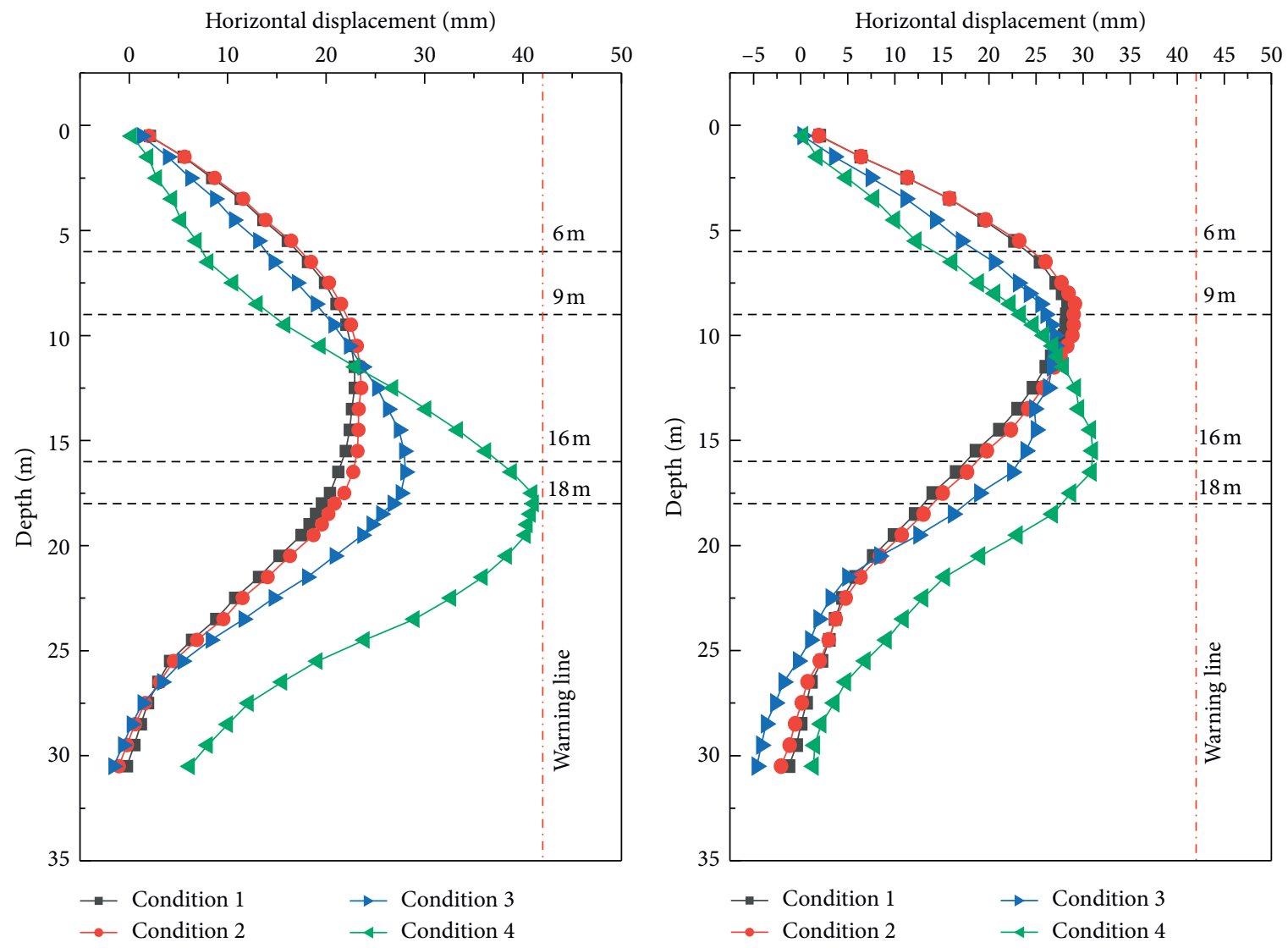

(a)

(b)

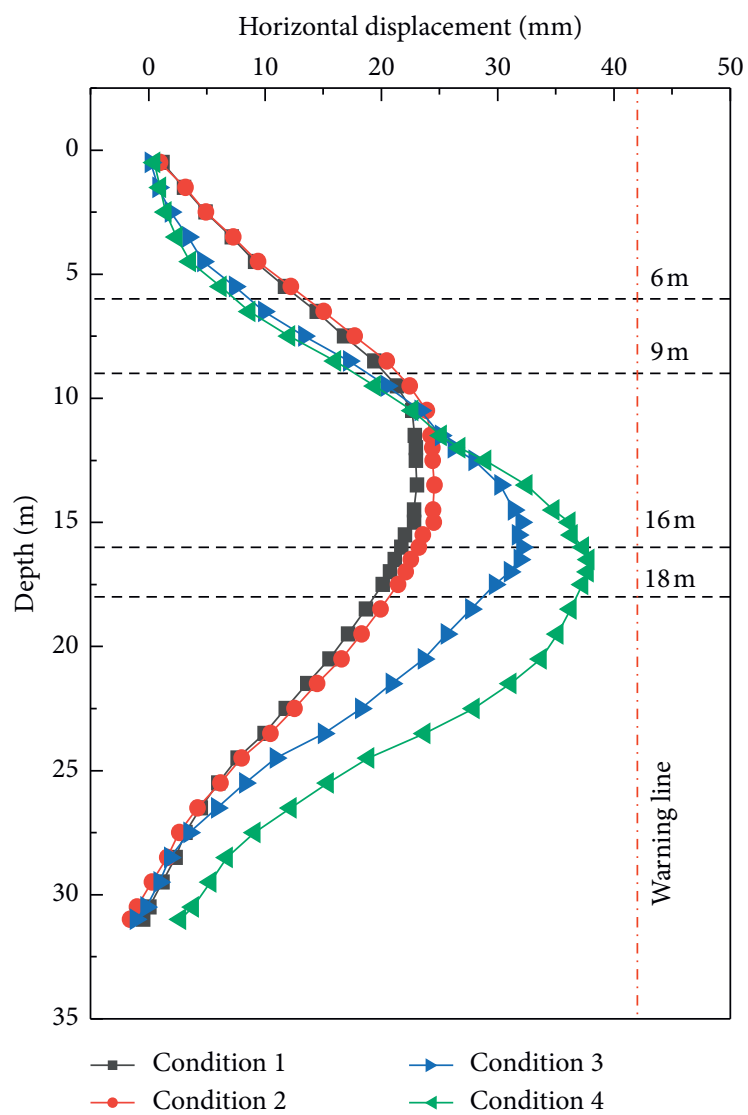

(c)

Figure 7: The relationship between the horizontal displacement of the retaining wall on the south side of the foundation pit and the excavation depth of the foundation pit. (a) Inclination point XY16; (b) inclination point XY17; and (c) inclination point XY18. 


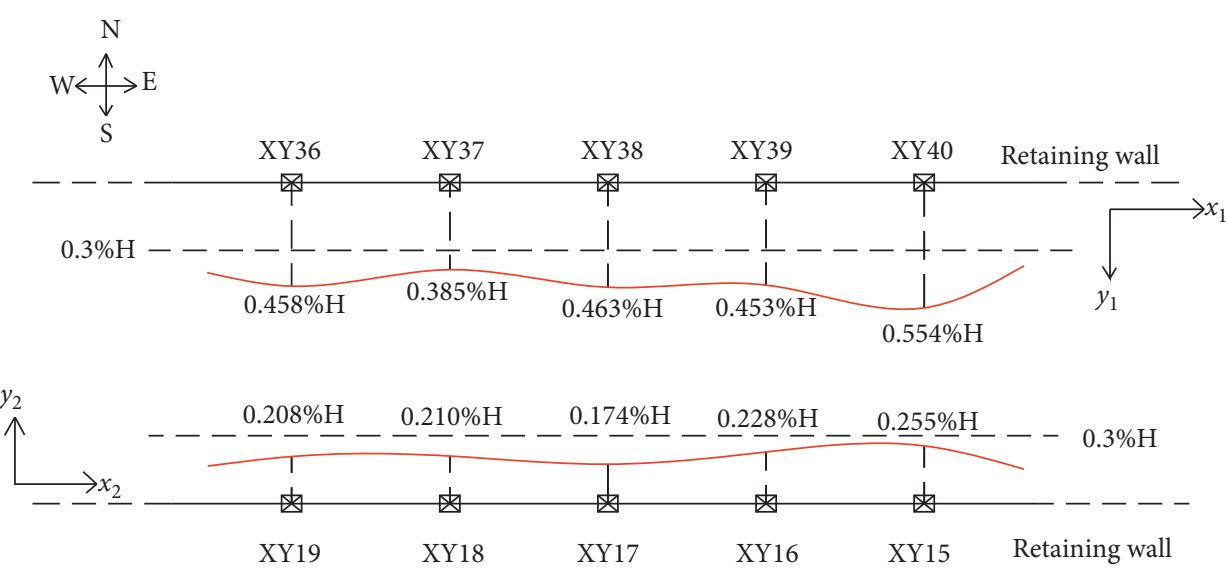

FIGURE 8: The deformation of the retaining walls on the north and south sides of the foundation pit.

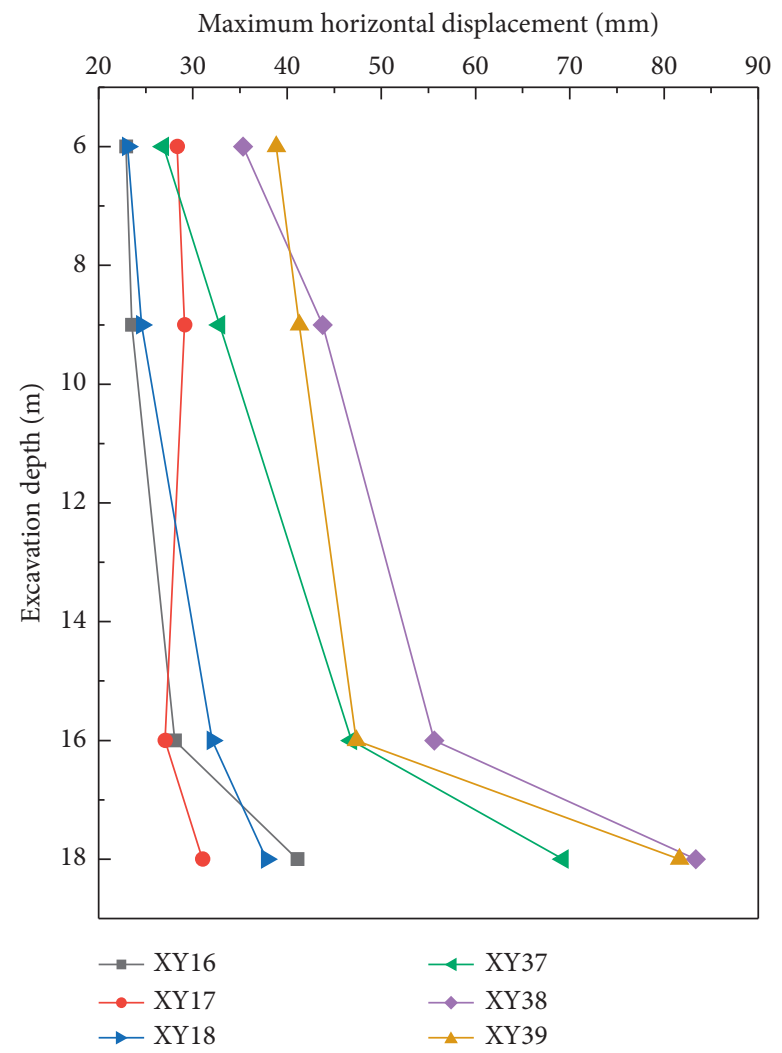

Figure 9: The variation in the maximum horizontal displacement of each inclination point with the excavation depth of the foundation pit.

studied foundation pit and that of a normal soft clay foundation pit are as follows:

(i) Under the conditions of overloading and unloading on the sides of the foundation pit, there is a difference in the magnitude of the active soil pressure on the northern and southern retaining walls and in the excavation depth corresponding to the calculated combined force; also, the backfill of the high-rise buildings on the north side has a certain time effect which causes the deformation of the northern and southern retaining walls and the depth corresponding to the maximum horizontal displacement of the retaining walls to be different. Moreover, the maximum horizontal displacement of the retaining walls obviously differs from the control value of an ordinary foundation pit.

(ii) The support settings in the excavated foundation pit on the south side are interlaced with the support settings in the present foundation pit, and there is a difference in the longitudinal distance between the two pit supports at the location of a certain area where measurement points XY16, 
XY17, and XY18 are located, which results in the different depths corresponding to the maximum horizontal displacement of the retaining wall on the south side.

(iii) During the fourth-level excavation process, the construction party did not arrange the construction schedule reasonably, and the exposure time of the foundation pit was too long, which intensified the time-space effect of the foundation pit. Therefore, an obvious turning point appears in the broken line in Figure 9.

(iv) In order to better deal with such problems, it is necessary to fully understand and evaluate the surrounding environment and to make adjustments in design and construction.

(v) For the high-rise residential buildings on the north side of the foundation pit, the overall stiffness of the fourth double-piece steel support should be raised in the foundation pit in the subway station.

(vi) The schedule of the construction of the foundation pit in the subway station should be fully coordinated with the construction schedule of the Evergrande foundation pit being excavated on the south side of the pit, and the excavation schedule should be better arranged to reduce the exposure time of the foundation pit and to reduce the time-space effect of the foundation pit.

(vii) It is recommended that on the side of the Evergrande pit close to the foundation pit in the subway station, the overall stiffness of the second and third supports should be strengthened and that the originally planned local area concrete slab structure should be changed to a full-area concrete slab structure in order to provide adequate force capacity and good overall stiffness during the excavation of the foundation pit.

(viii) The bottom of the foundation pit is located in the silty clayey clay and silt layer (6 ${ }_{2}$ in Figure 1), which is slightly impermeable and weakly water-rich, so drainage work should be done to reduce water and soil pressure during the excavation process.

\subsection{Comparative and Predictive Analyses of Surface Settlement}

3.2.1. Comparative Analysis of Surface Settlement. Figure 10 shows the variation in the monitored data on the surface settlement with the depth of the excavation of the foundation pit. In this figure, the surface settlement is negative, and the uplift is positive; $\sigma_{\mathrm{vm}}$ represents the maximum surface settlement.

According to this figure, there is a major difference in the surface settlement on the north and south sides of the foundation pits. Comparing CJ38-1 with CJ17-1 with the same distance of $2 \mathrm{~m}$ from the retaining wall of the foundation pit reveals that the settlement on the north side is much larger than

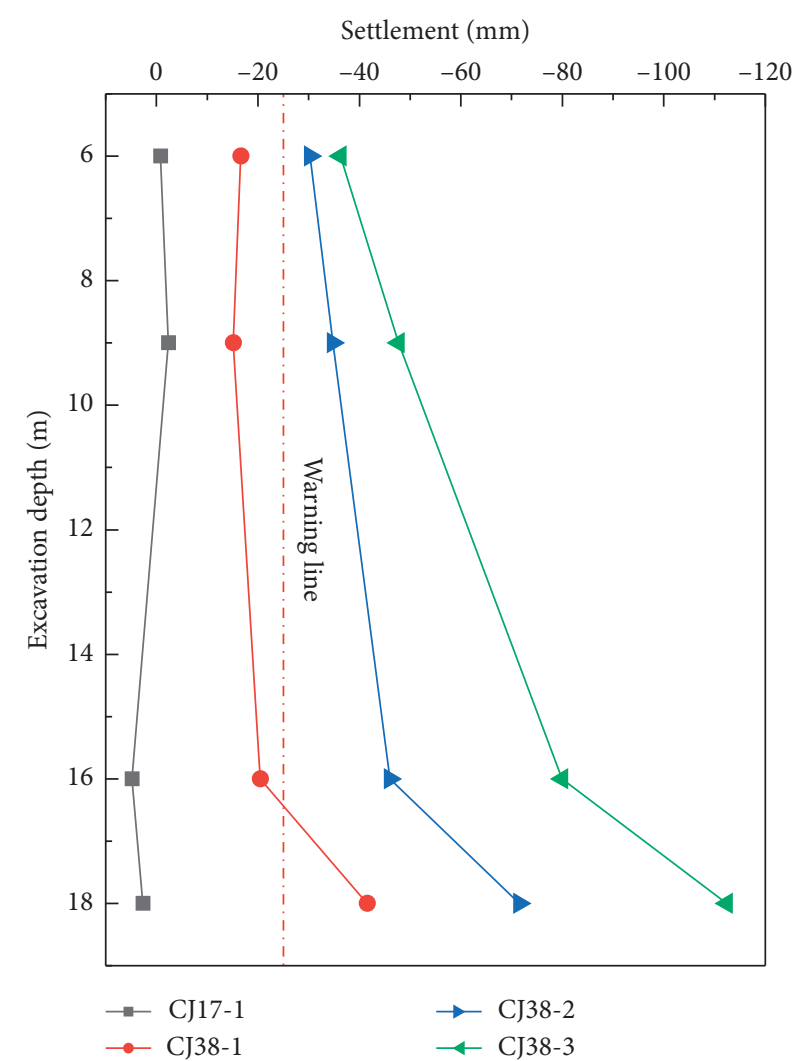

FIgURE 10: The variation in the surface settlement with the excavation depth of the foundation pit.

that on the south side of the foundation pit and that there is an uplift at CJ17-1 in the later stage of excavation. The ground subsidence at CJ38-1 exceeds the alarm value. In addition, the ground subsidence measured at CJ38-2 and CJ38-3 on the north side of the foundation pit exceeds the warning value under all the conditions, and the surface subsidence at the three measurement points increases significantly at the last level of the excavation of the foundation pit.

Firstly, overloading and unloading of the adjacent pit wall are the main cause of the difference between the ground settlement on the north and south sides of the foundation pit. Secondly, during the excavation of the foundation pit, there was a large accumulation of steel nearby and the continuous rolling of large engineering vehicles as shown in Figure 3. Finally, the final level of the excavation left the foundation pit was exposed to the air for too long. Therefore, during the construction process, the site needs to be strictly controlled in order to prevent temporary stacking as well as cyclic loading from having a marked influence on the ground settlement.

3.2.2. Comparative Analysis of Surface Settlement and Predicted Data. Ding et al. [13], Yu et al. [14], and Hsieh et al. [15], after studying the deformation of numerous deep foundation pits in soft soil, concluded that the maximum surface settlement occurs at $H_{m}$ behind the retaining wall. For the north side of the foundation pit, the farther the distance from the edge of the pit is, the greater the ground 
settlement becomes. Furthermore, there is no parabolic settlement curve as suggested by Ding et al. [16] and $\mathrm{V}$-shaped settlement curve as reported by Hsieh et al. [15] chiefly because there are few settlement monitoring points; thus, further prediction and analysis should be conducted. However, there is only one settlement measurement point on the south surface, and the ground settlement is not obvious; hence, the predicted value of the ground settlement on this side is not discussed.

Hsieh et al. [15] analyzed the deformation characteristics of the soil outside the foundation pit and obtained the prediction curve of the surface settlement of an ordinary foundation pit; they validated the prediction curve by the measured data on the soft clay foundation pit. The verification revealed that the prediction curve of the surface settlement is in good agreement with the measured data; the surface settlement is defined as

$$
\left\{\begin{array}{l}
\delta_{\mathrm{vm}}\left(\frac{x}{H}+0.5\right), \quad 0 \leq x \leq 0.5 H, \\
\delta_{\mathrm{vm}}\left(\frac{-0.6 x}{H}+1.3\right), \quad 0.5 H \leq x \leq 2 H, \\
\delta_{\mathrm{vm}}\left(\frac{-0.05 x}{H}+0.2\right), \quad 2 H \leq x \leq 4 H,
\end{array}\right.
$$

where $x$ is the distance from the surface settlement point to the foundation pit wall, $\delta(x)$ represents the amount of the surface settlement, and $H$ stands for the depth of the excavation of the foundation pit.

Figure 11 compares the prediction of the surface settlement on the north side of the foundation pit with the measured data. It is worth noting that the settlement measured at CJ38-3 at a distance of $11 \mathrm{~m}$ from the foundation pit wall is below the predicted line under the conditions of the four-stage excavation; also, when the depth of the excavation reaches $18 \mathrm{~m}$, the surface settlement exceeds $25 \%$ of the predicted maximum value. Since there are few measuring points on the north side of the foundation pit, the position of the maximum surface settlement cannot be judged from the measured data alone. However, it can be inferred from the trend of the prediction curve that, regardless of the position of the maximum surface settlement on the north side of the foundation pit in the range of 0 to $0.5 H_{m}$ or beyond $0.5 H_{m}$, measurement point CJ38-3 at a distance of $11 \mathrm{~m}$ from the foundation pit wall is not the corresponding position of the maximum surface settlement. Therefore, the authors suggest that the ground surface of the foundation pit adjacent to the high-rise residential buildings or under other loading conditions can expand the measurement range; for the foundation pit in this work, the measurement range can be expanded to $2 H_{m}$.

3.3. Comparative Analysis of Creep of Soil. The consolidation and creep of soil are the main causes of the horizontal displacement of the soil body and the continued increase in the surface settlement during the gap period of the excavation of the foundation pit. Through the finite element simulation of the effect of the excavation time of a soft clay deep foundation pit, Ying et al. [17] reported that, during the excavation of the pit, the excavation of the upper soil leads to the dissipation of the superstatic negative pore pressure, which then results in the continued horizontal displacement of the soil in the foundation pit wall and the continued slight retraction of the surface soil. Due to the insignificant dissipation of the superstatic negative pore pressure in the foundation pit in this work and the short gap period of the excavation of the foundation pit, the effect of soil consolidation is ignored herein.

Accordingly, the incremental horizontal soil displacement of the retaining wall of the foundation pit during the gap period of the excavation of the studied foundation pit is defined as the horizontal creep of the soil and the creep caused by the surface settlement. The maximum rate of the creep caused by the horizontal soil displacement $(\alpha)$ and the maximum rate of the creep caused by the surface settlement $(\mu)$ are expressed by

$$
\begin{aligned}
& \alpha=\frac{\Delta}{T}, \\
& \mu=\frac{\nabla}{T},
\end{aligned}
$$

where $\Delta$ and $\nabla$ are defined as the gap period of the excavation of the foundation pit at the maximum increment in the horizontal displacement of the soil and at the maximum increment in the settlement of the surface soil, respectively; $T$ is the time interval of the gap period of the excavation of the foundation pit. Due to the shallow excavation depth of $6 \mathrm{~m}$, the creep effect is not remarkable; thus, the soil creep at this depth is not discussed herein.

\subsubsection{Comparative Analysis of Horizontal Creep of Soil.} Figure 12 illustrates the distribution of the maximum rate of the horizontal creep of the soil in the wall of the foundation pit with the depth of the excavation. As can be seen in this figure, the maximum rate of the creep of the soil in the wall of the foundation pit is significantly higher on the north side than on the south side; further, the higher the depth of the excavation is, the more remarkable the difference between the two sides becomes. For the excavation of ordinary foundation pits, the maximum rate of the horizontal creep summarized by Ou et al. [18] and Ying et al. [19] ranges from 0.1 to $0.6 \mathrm{~mm} /$ day and from 0.15 to $0.76 \mathrm{~mm} /$ day, respectively. For the foundation pit in this work that is overloaded on one side and unloaded on the other side, the maximum rate of the creep of the soil on the north side of the foundation pit is between 0.06 and $1.68 \mathrm{~mm} /$ day, and that on the south side of the foundation pit is between 0 and $0.2 \mathrm{~mm} /$ day. Therefore, the maximum rate of the creep of the soil on the north side of the foundation pit under the overloading conditions is slightly larger than that of the soil of the ordinary foundation pit, while the maximum rate of the creep of the soil on the south side under the unloading conditions is slightly lower than that of the soil of the ordinary foundation pit. 


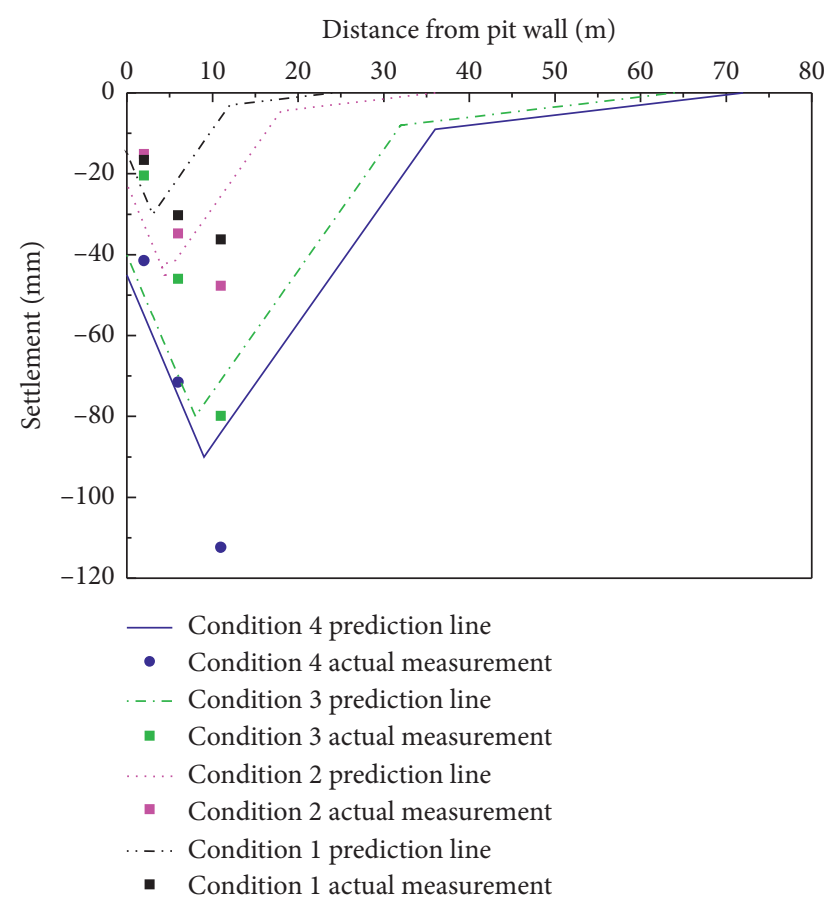

FIGURE 11: The comparison between the measured data on the surface settlement on the north side of the foundation pit and the predicted surface settlement.

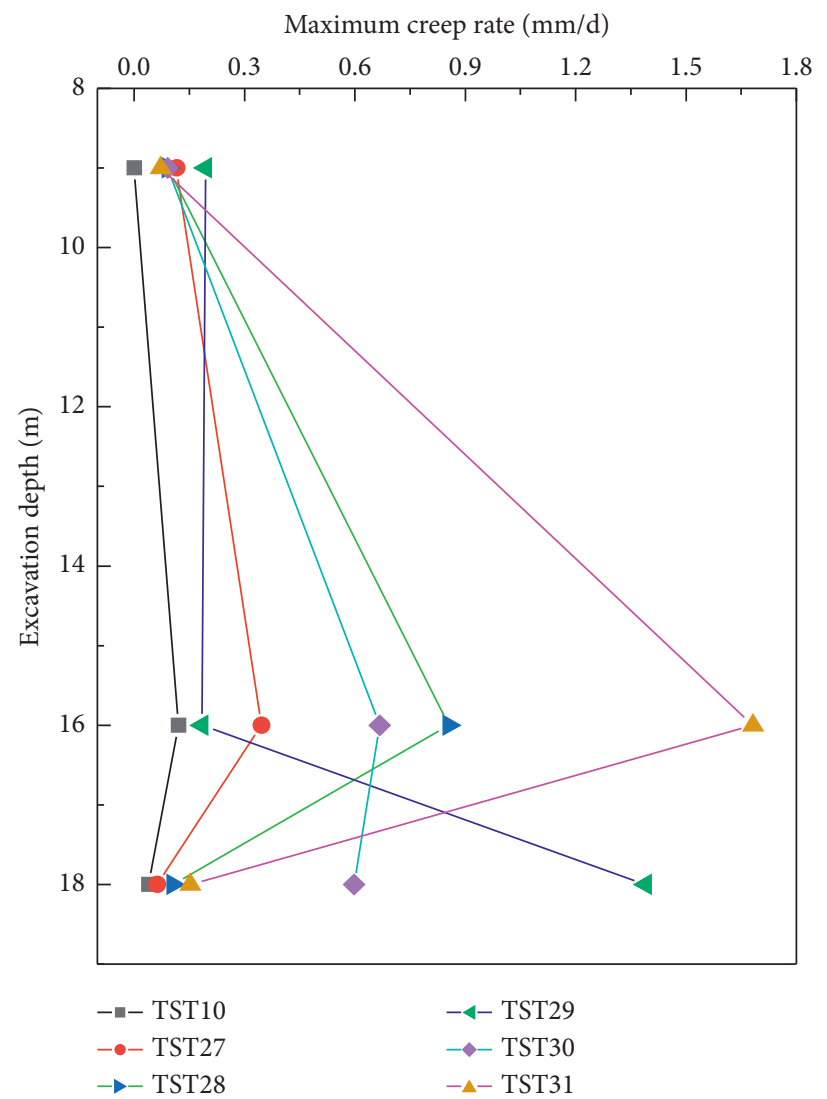

FIgURe 12: The variation in the maximum rate of the horizontal creep of the soil in the wall of the foundation pit with the depth of the excavation. 
3.3.2. Comparative Analysis of Surface Settlement and Corresponding Creep. Figure 13 delineates the variation in the maximum rate of the creep caused by the surface settlement with the depth of the excavation. The maximum rate of the creep caused by the surface settlement is significantly larger on the north side than on the south side of the foundation pit, and the higher the depth of the excavation is, the more significant the difference between the two sides becomes. For the excavation of ordinary pits, Ou et al. [18] and Ying et al. [19] summarized the maximum rate of the creep caused by the surface settlement in the range of 0.1 to $0.4 \mathrm{~mm} /$ day and 0.1 to $0.6 \mathrm{~mm} /$ day, respectively. The maximum rate of the creep caused by the ground settlement on the north side of the foundation pit is between 0.05 and $1.54 \mathrm{~mm} /$ day, and that on the south side of the foundation pit ranges from 0.16 to $0.64 \mathrm{~mm} /$ day. In fact, the maximum rate of the creep caused by the ground settlement on the north side of the foundation pit under the overloading conditions is slightly larger than the maximum rate of the creep of the ordinary foundation pit, while the maximum rate of the creep caused by the ground settlement on the south side of the foundation pit under the unloading conditions is equivalent to it.

Thus, the difference between the rates of the creep of the foundation pit on the north and south sides and the contrast between the rate of the creep of the studied foundation pit and that of the ordinary foundation pit are chiefly due to the following two reasons:

(1) The north side of the foundation pit is adjacent to the new high-rise residential buildings; that is, it is under the overloading conditions, and the south side is adjacent to the foundation pit being excavated; that is, it is under the unloading conditions.

(2) There are often large construction vehicles continuously moving on the north side of the foundation pit, so the creep effect on this side will be aggravated under the action of this cyclic load.

In this regard, in the process of the excavation of foundation pits, especially for such "hard top and soft bottom" soil layers, the shear strength of the soil is weak and the compressibility of the soil is high. Hence, it is necessary to strengthen the support rigidity, reduce the surface overload, and weaken the action of the cyclic loads on the adjacent surface. When the excavation is nearing completion, the cushion and bottom plate must be poured in time.

\subsection{Comparison of Active Soil Pressure on Northern and} Southern Walls. In the actual conditions of the excavation of the foundation pit, the active and passive soil pressure zones are often switched, but the active soil pressure zone above the bottom of the foundation pit is basically stable. Thus, this paper focuses on the active soil pressure zone above the bottom of the foundation pit and analyzes the influence of overloading and unloading the perimeter of the foundation pit on the horizontal displacement of the retaining wall of the foundation pit from the viewpoint of the active soil pressure on the foundation pit wall.
In calculating the effect of overloading on the active soil pressure, the Rankine Earth pressure theory can be used to simplify the load of the high-rise residential buildings to a local load adjacent to the foundation pit wall, as shown in Figure 14 [20].

In Figure 14, assuming neither unloading nor overloading conditions, the shaded portion of area $S_{\mathrm{ADCB} f g}$ represents the active soil pressure on the $\mathrm{AB}$ wall. In the near overloading situation, shaded area $S_{\mathrm{ADCB} \text { cdefg }}$ indicates the active Earth pressure on the $\mathrm{AB}$ wall. Obviously, $S_{\mathrm{ADCB} \text { defg }}$ is larger than $S_{\mathrm{ADCBcfg}}$, so the active soil pressure on the wall near the overloaded side of the enclosure is higher; thus, the horizontal displacement of the retaining wall of the foundation pit in the subway station is larger than that of the ordinary foundation pit.

The unloading conditions outside of the pit can be considered as negative overloading conditions [21], so the active Earth pressure on the retaining wall of the foundation pit on the south side is lower than that on the wall of the ordinary foundation pit. As a result, the horizontal displacement of the retaining wall of the foundation pit adjacent to the unloading side of the enclosure is smaller than that of the ordinary foundation pit, which results in a downward shift of the position of the combined Earth pressure. Therefore, the maximum horizontal displacement of the retaining wall of the foundation pit adjacent to the unloading side of the enclosure corresponds to a depth that is often lower than that of the ordinary foundation pit. In addition, as presented in Figure 7, the displacement at the bottom of the retaining wall on the south side of the foundation pit is clearly biased toward the outside of the foundation pit. The reason for the above phenomenon is that the retaining wall of this foundation pit on the south side is close to the excavation of the Evergrande pit; that is, it is under the unloading conditions, which reduces the active soil pressure on the wall of the foundation pit and causes the bottom of the retaining wall to produce a large passive soil pressure.

3.5. Analysis of Settlement of Surrounding Buildings and Columns. Figure 15 illustrates the variation in the monitored data with the depth of the excavation for the four settlement measurement points in building 5 , where the settlement is negative. With the excavation of the foundation pit, the settlement of the building increases, and the closer to the building the location of the foundation pit is, the larger the settlement of the building becomes. However, the difference in the settlement of the measurement points is not crucial and does not exceed the warning value of $20 \mathrm{~mm}$, so the settlement has a small impact on the building. At the final level of the excavation of the foundation pit, the increase in the settlement of the building is accelerated for the same reasons as in the above analysis.

Figure 16 delineates the monitored data at the measurement point of the column settlement as a function of time, where the column elevation is a positive value and the column settlement is a negative value. With the continuous excavation of the foundation pit, the measurement points of the column settlement measure positive values, which 


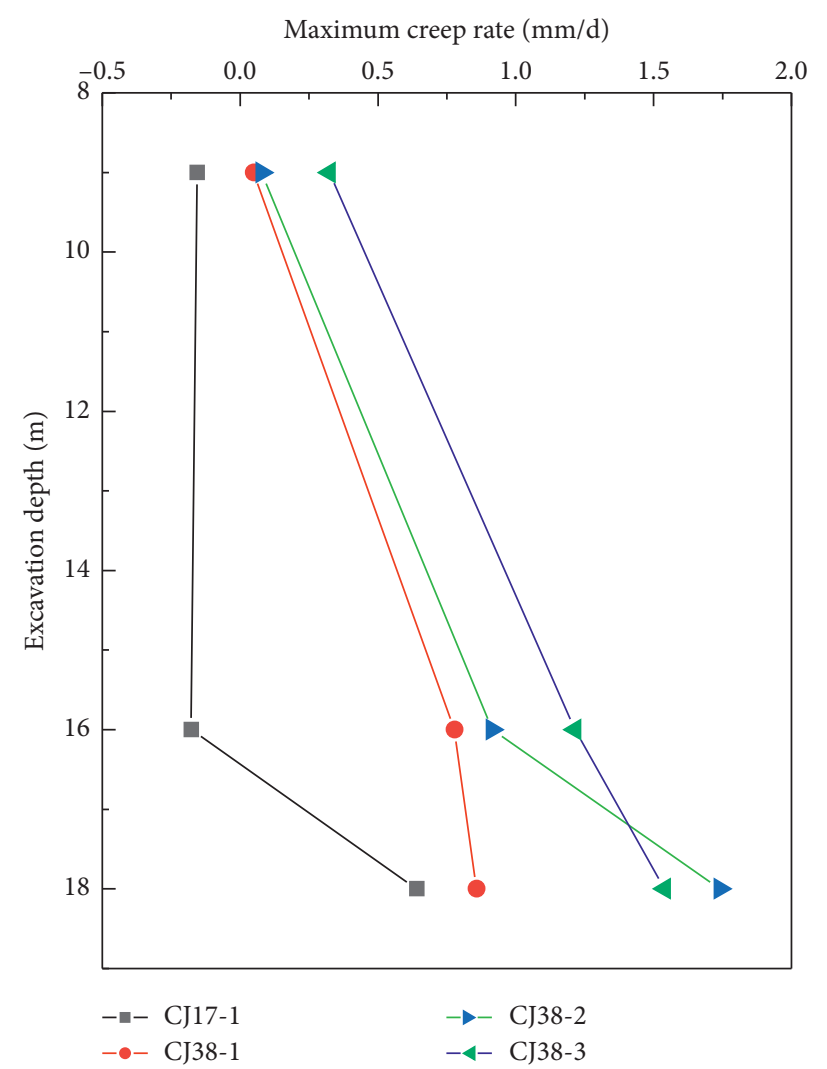

FIGURE 13: The variation in the maximum rate of the creep caused by the surface settlement with the excavation depth of the foundation pit.

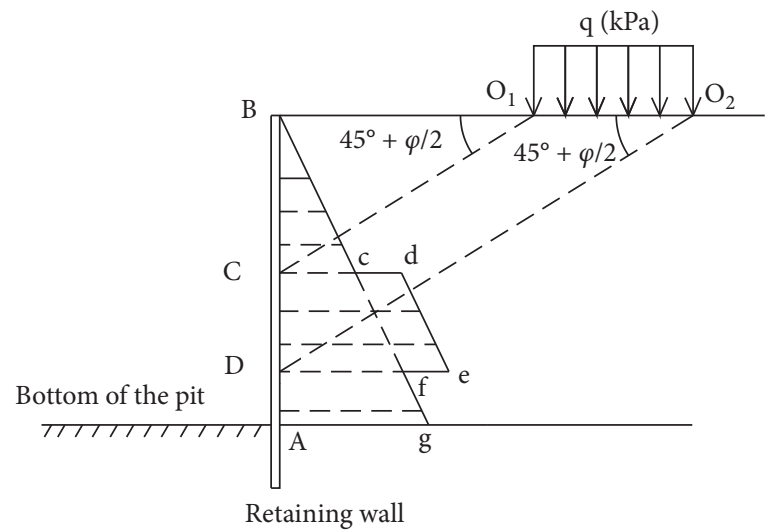

FIgURE 14: A schematic diagram of the active Earth pressure near the overloaded side of the foundation pit [20].

indicates the continuous uplifting of the bottom of the foundation pit; indeed, the deeper the foundation pit is, the more pronounced the bulge of the foundation pit becomes. Nevertheless, it does not exceed the warning value of $20 \mathrm{~mm}$ of the column settlement, which is attributed to the existence of a foundation pit being excavated on the south side of the foundation pit in the subway station; its existence has an unloading effect on the foundation pit in the subway station. After November 5, 2017 (the excavation of the foundation pit to a depth of $18 \mathrm{~m}$ ), the uplift of the base was significantly reduced because of the cushion and bottom plate laid at the bottom of the foundation pit. 


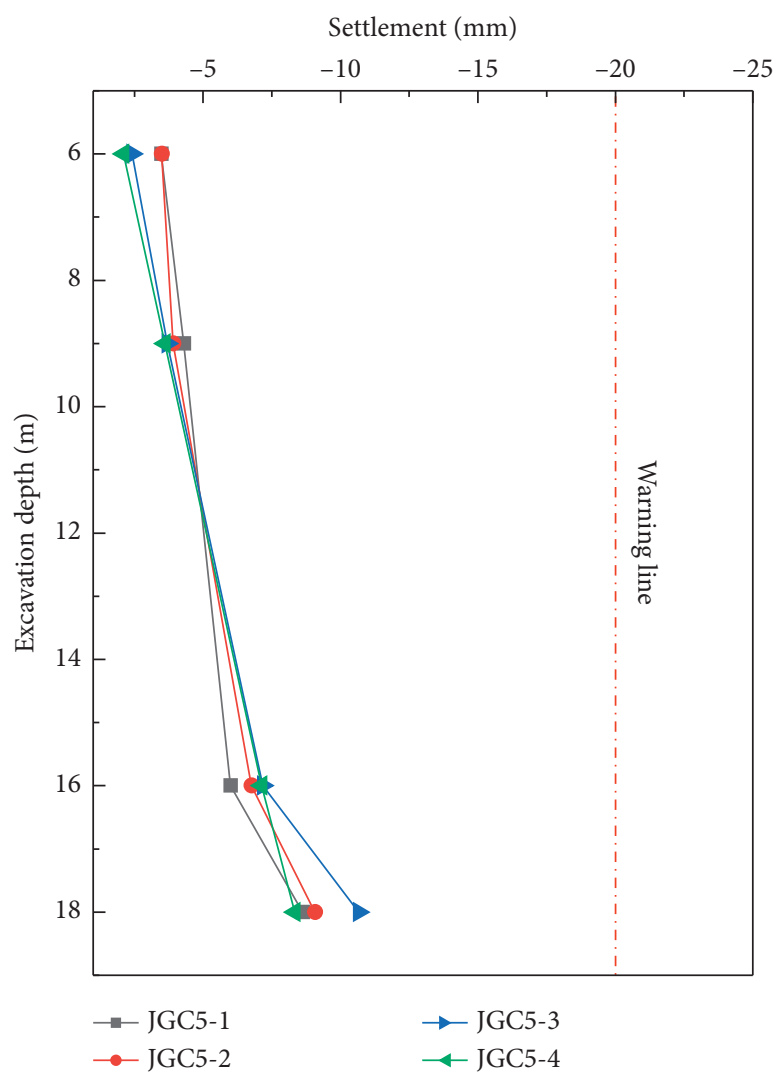

FIGURE 15: The variation in the settlement of the surrounding buildings with the excavation depth of the foundation pit.

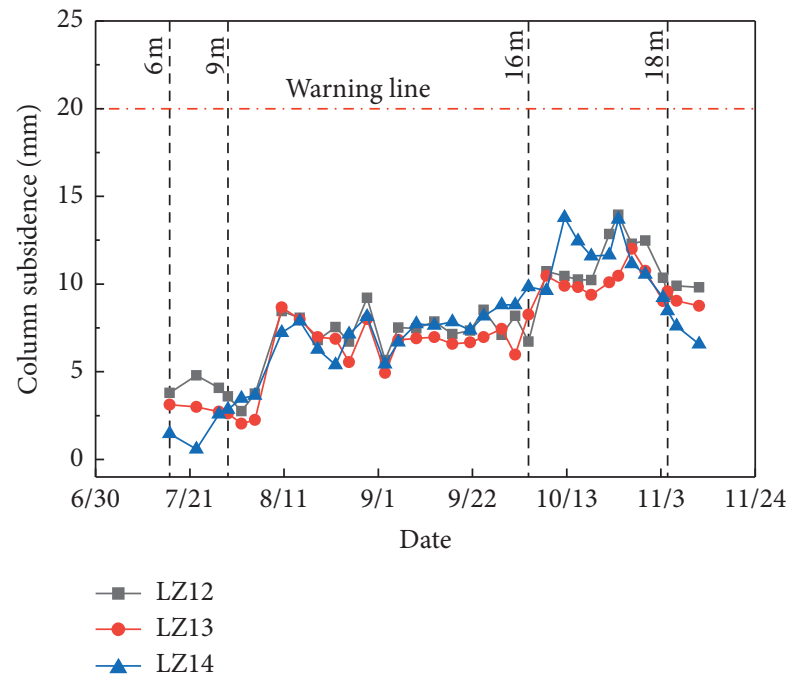

FIGURE 16: The variation in the column settlement with time.

\section{Conclusions}

The conclusions that follow from the findings of this work are summarized below:

(i) The horizontal displacement and surface settlement of the retaining walls of the foundation pit on the north and south sides of the pit are not symmetrical and uniform, so the deformation of the foundation pit in the subway station markedly differs from that of a common foundation pit. Since the north side of the foundation pit in the subway station is adjacent to the new high-rise residential buildings (under overloading conditions), the south side of the foundation pit is adjacent to the Evergrande foundation pit being excavated (under unloading conditions), and the backfill of the high-rise buildings on the north side of 
the foundation pit has a certain time effect, the deformation of the overloaded side is more remarkable than that of the unloaded side and generally exceeds the warning value; the deformation of the common foundation pit is between the deformation of the overloaded side and that of the unloaded side. Therefore, it is important to strengthen the support stiffness, reduce and control the additional overload, and rationalize the construction schedule. In addition, expanding the scope of the surface settlement monitoring on the overloading side is recommended.

(ii) For both the horizontal creep of the foundation pit wall and the creep caused by the surface settlement of the foundation pit wall, the maximum rate of the creep is larger on the overloading side than on the unloading side, while the maximum rate of the creep of the ordinary foundation pit is generally between the two. The study found that, in addition to the load of the high-rise buildings on the north side, the load of the vehicle movement exacerbates the creep effect.

(iii) According to the Rankine earth pressure theory, the active earth pressure on the pit wall is higher on the overloading side of the foundation pit than on the unloading side, and the depth of the calculated synergistic effect on the unloading side will be shifted downward. Also, the displacement at the bottom of the retaining wall adjacent to the south side of the pit is deviated to the outside of the foundation pit, which is caused by the passive earth pressure at the bottom of the retaining wall of the foundation pit.

(iv) The settlement of the high-rise buildings on the north side of this foundation pit and the settlement of the columns are within the range of the alarm value, and the settlement of the high-rise buildings is uniform. Therefore, the excavation of the foundation pit in the station of the Hangzhou subway has a negligible impact on the settlement of the high-rise residential buildings. Furthermore, the existence of the Evergrande foundation pit being excavated on the south side of this foundation pit has a certain unloading effect, which causes the column elevation not to be noticeable.

\section{Data Availability}

The data used to support the findings of this study are included within the article.

\section{Conflicts of Interest}

The authors declare that they have no conflicts of interest regarding the publication of this paper.

\section{Acknowledgments}

The authors would like to acknowledge the financial support from the National Natural Science Foundation of China (NSFC) (Grant no. 51808492).

\section{References}

[1] T. Bhatkar, D. Barman, A. Mandal, and A. Usmani, "Prediction of behaviour of a deep excavation in soft soil: a case study," International Journal of Geotechnical Engineering, vol. 11, no. 1, pp. 10-19, 2017.

[2] K. Elbaz, S.-L. Shen, Y. Tan, and W.-C. Cheng, "Investigation into performance of deep excavation in sand covered karst: a case report," Soils and Foundations, vol. 58, no. 4, pp. 1042-1058, 2018.

[3] P.-G. Hsieh and C.-Y. Ou, "Simplified approach to estimate the maximum wall deflection for deep excavations with cross walls in clay under the undrained condition," Acta Geotechnica, vol. 11, no. 1, pp. 177-189, 2016.

[4] A. L. Gotman and Y. A. Gotman, "Numerical analysis of the shorings of deep foundation pits with regard for the soil solidification," Soil Mechanics and Foundation Engineering, vol. 56, no. 4, pp. 225-231, 2019.

[5] B.-C. B. Hsiung, "Observations of the ground and structural behaviours induced by a deep excavation in loose sands," Acta Geotechnica, vol. 15, no. 6, pp. 1577-1593, 2020.

[6] J. Shi, J. Liu, Y. Wu, and Y. Liu, "Analysis of the influence of subway entrance excavation on tunnel and adjacent buildings," IOP Conference Series: Earth and Environmental Science, vol. 371, p. 022037, 2019.

[7] R. A. Mangushev, A. I. Osokin, and L. V. Garnyk, "Experience in preserving adjacent buildings during excavation of large foundation pits under conditions of dense development," Soil Mechanics and Foundation Engineering, vol. 53, no. 5, pp. 291-297, 2016.

[8] Z. Wang and C. Wang, "Analysis of deep foundation pit construction monitoring in a metro station in jinan city," Geotechnical and Geological Engineering, vol. 37, no. 2, pp. 813-822, 2019.

[9] Z. Ding, J. Wang, Y. Zhou et al., "Monitoring analysis of the interrelationship of synchronous construction in adjacent foundation pit," China Civil Engineering Journal, vol. 48, no. 2, pp. 124-130, 2015, in Chinese.

[10] H. Shi, C. Ge, Z. Liu et al., "Study on interaction of two adjacent excavations constructed simultaneously," Chinese Journal of Underground Space and Engineering, vol. 11, no. S1, pp. 183-188, 2015, in Chinese.

[11] F. Zeng, Z. Zhang, J. Wang et al., "Observed performance of two adjacent and concurrently excavated deep foundation pits in soft clay," Journal of Performance of Constructed Facilities, vol. 32, no. 4, Article ID 04018040, 2018.

[12] Zhejiang Province Institute of Architectural Design and Research, DB33/T1096-2014 Code for technique of Building Foundation Excavation Engineering, China Architecture \& Building Press, Beijing, China, 2014, in Chinese.

[13] Z. Ding, D. Wang, J. Wang et al., "Deformation characteristics of Zhejiang soft soil deep foundation pits and their predictive analysis," Rock and Soil Mechanics, vol. 36, no. 1, pp. 506-512, 2015, in Chinese.

[14] J. Yu, X. Gong, and Y. Li, "Deformation characteristics of deep excavations based on mess data," Chinese Journal of Geotechnical Engineering, vol. 36, no. 2, pp. 319-324, 2014, in Chinese.

[15] P.-G. Hsieh and C.-Y. Ou, "Shape of ground surface settlement profiles caused by excavation," Canadian Geotechnical Journal, vol. 35, no. 6, pp. 1004-1017, 1998.

[16] Z. Ding, D. Wang, X. Yu et al., "Monitoring and analysis of deep foundation pit at Xintang Road-Jingfang Road cross of 
Hangzhou metro," Chinese Journal of Geotechnical Engineering, vol. 35, no. 2, pp. 445-451, 2013, in Chinese.

[17] H. Ying, K. Xie, Q. Pan et al., "FEM analysis on time-effects of deep excavations in soft clay," Chinese Journal of Computational Mechanics, vol. 17, no. 3, pp. 349-354, 2000, in Chinese.

[18] C.-Y. Ou, J.-T. Liao, and H.-D. Lin, "Performance of diaphragm wall constructed using top-down method," Journal of Geotechnical and Geoenvironmental Engineering, vol. 124, no. 9, pp. 798-808, 1998.

[19] H. Ying, W. Sun, M. Lv et al., "Measured characteristics of a deep soft soil excavation in complex environment," Chinese Journal of Geotechnical Engineering, vol. 36, no. 2, pp. 424430, 2014, in Chinese.

[20] J. Qian, J. Yuan, C. Zhao et al., Soil Properties and Soil mechanicsp. 156, 2015, in Chinese, 5th edition.

[21] Q. Gong, M. Tang, and S. Zhou, "Study on active earth pressure behind the retaining wall of a foundation pit influenced by neighboring unloading," Chinese Journal of Underground Space and Engineering, vol. 3, no. 5, pp. 872877, 2007, in Chinese. 